\title{
A QUESTÃO DE GÊNERO E AS AÇÕES DO PIBID-HISTÓRIA DA UFTM
}

\section{THE QUESTION OF GENDER AND THE ACTIONS OF UFTM'S PIBID-HISTORY}

\author{
Ilana Peliciari Rocha ${ }^{1}$ \\ Marcelo de Souza Silva²
}

\begin{abstract}
Resumo: Este artigo se propõe apresentar uma discussão acerca de projetos de intervenção relacionados às questões de gênero, entremeados pelos debates sobre raça e racismo, que foram desenvolvidos no Programa Institucional de Bolsa de Iniciação à Docência (PIBID), subprojeto de História, na Universidade Federal do Triângulo Mineiro (UFTM). As ações ocorreram com grupos distintos de bolsistas e estudantes, num período entre 2017 e 2019. Os projetos foram aplicados em escolas de educação básica do município de Uberaba-MG, apresentam como foco a formação de futuros(as) professores(as)-historiadores(as). Ocorreram concomitante a intensos confrontos relacionados ao trabalho com gênero nas escolas municipais de Uberaba. A partir de uma perspectiva interdisciplinar e da compreensão de que os(as) professores(as) devem se formar aprendendo a fazer a correlação entre teoria e prática, o conceito de gênero pode ser trabalhado e os preconceitos e imprecisões sobre o tema acabaram servindo como catalisadores para maior participação dos(as) envolvidos(as).
\end{abstract}

Palavras-chave: Gênero. PIBID. História. Educação

\begin{abstract}
This article proposes to present a discussion about intervention projects related to gender issues, interspersed by the debates about race and racism, which were developed in the Institutional Scholarship Program for Initiation to Teaching (PIBID), subproject of History, at the University Federal do Triângulo Mineiro (UFTM). The actions took place with different groups of scholarship holders and students, in a period between 2017 and 2019. The projects were applied in basic education schools in the city of Uberaba-MG, focusing on the training of future teachers-historians (at). They occurred concurrently with intense confrontations related to gender work in municipal schools in Uberaba. From an interdisciplinary perspective and the understanding that teachers should be trained by learning to make the correlation between theory and practice, the concept of gender can be worked on and the prejudices and inaccuracies on the subject ended up serving as catalysts for greater participation of those involved.
\end{abstract}

Keywords: Gender. PIBID. Story. Education

Introdução

\footnotetext{
${ }^{1}$ Doutora em História Econômica pela USP. Professora Adjunta no curso de licenciatura em História da Universidade Federal do Triângulo Mineiro. Uberaba, Minas Gerais, Brasil, email: ilana.peliciari@uftm.edu.br

2 Universidade Federal do Triângulo Mineiro
} 
Dossiê: Ensino de História, História das Mulheres e Desigualdades Sociais no Brasil

As questões de gênero vêm ganhando espaço ao longo dos últimos anos e aparecem como campo de disputas políticas. Os espaços escolares tornaramse ambientes nos quais essas disputas se escancararam. Alguns grupos passaram a condenar o trabalho com temas relacionados e até mesmo chegaram à judicialização da questão.

Nessa mesma perspectiva, o Programa Institucional de Bolsas de Iniciação à Docência (PIBID) também se viu inserido nestes campos de disputas, exigindo mobilização das Instituições de Ensino Superior e das escolas de Educação Básica para sua manutenção.

Como espaço formativo, o PIBID tornou-se ao longo da última década o mais importante programa para o desenvolvimento de abordagens e conteúdos que envolvem a realidade dos(as) estudantes e as problemáticas da vida em sociedade, contribuindo de uma forma ainda não facilmente mensurável, para criação de uma geração de professoras e professores com novas habilidades capazes de fazerem progressos na qualidade do ensino em geral.

O PIBID foi criado como parte das ações do Política Nacional de Formação de Professores desenvolvido pelo MEC a partir de 2008. Ele concede bolsas a estudantes de licenciatura para atuarem em projetos de intervenção pedagógica em escolas públicas de ensino básico, os quais são orientados tanto pelo(a) professor(a) da escola - chamado(a) supervisor(a) - quanto pelo(a) professor(a) da Instituição de Ensino Superior ao qual ficam vinculados os programas localmente, ambos também recebem bolsa. Cada instituição tem o seu projeto, dividido em subprojetos conforme as licenciaturas presentes, e isso fez com que as experiências no PIBID sejam bastante variadas por todo o Brasil. Porém, essa situação não afastou as diferentes instituições do objetivo primordial, qual seja, o de elevar a qualidade da formação docente fazendo com que os(as) licenciandos(as) vivenciassem a realidade escolar em outro contexto diferente do estágio supervisionado, para que pudessem pôr em prática aquilo que aprendiam na universidade de forma mais prolongada e planejada.

O desenvolvimento de pesquisas e a emersão do debate em torno de questões gênero manifestam-se como campo de ação para atividades desenvolvidas pelo PIBID desde a sua criação na Universidade Federal do Triângulo Mineiro. O programa de iniciação à docência está presente no curso 
Dossiê: Ensino de História, História das Mulheres e Desigualdades Sociais no Brasil

de História da UFTM - criado em 2009 - desde 2011 e foi gestado em consonância com a perspectiva "de que o licenciando deve vivenciar o cotidiano escolar para compreender, em interação com os supervisores, as possibilidades e limites da atuação docente" (ROCHA \& SILVA, p. 161, 2019). Partindo dessa perspectiva, o planejamento das atividades levou em consideração as necessidades das escolas envolvidas e os debates sobre ensino de História, contando também com a participação das secretarias estadual e municipal de ensino locais.

A primeira experiência do curso de História da UFTM no PIBID se deu com a participação dos (as) docentes no projeto institucional apresentado à CAPES a partir da demanda do edital 01/2011. Naqueles momentos iniciais, vários foram os desafios, especialmente quanto às formas de atuação e de articulação da formação docente em diferentes espaços, da universidade às salas de aula do ensino básico. A partir das experiências adquiridas nestes anos iniciais, formatou-se o subprojeto de História que fez parte do projeto institucional encaminhado para concorrer no edital 061/2013, cujas atividades ocorreram entre 2014 e 2018. Desde o início, o trabalho com o PIBID se mostrou desafiador ao corpo docente, posto que eles tiveram que repensar seus próprios processos formativos, suas atuações no ensino básico e superior, para buscar, em diálogo com os professores(as) supervisores(as) e os(as) bolsistas de iniciação à docência (bolsistas de ID), as melhores formas de intervenção nas escolas.

[...] o PIBID surgiu como uma importante provocação e também contribuição ao curso de História. Todas as práticas e ações planejadas e desenvolvidas no Programa pautaram-se pela relação dialógica entre Teoria e Didática da História, com vista a formar um professor-pesquisador (SILVA, COSTA \& OLIVEIRA, 2018, p. 52).

Sendo assim, o desenvolvimento das ações no âmbito do subprojeto sempre se deu a partir da observação de que os(as) licenciandos(as) deveriam se inserir no cotidiano escolar, vivenciar experiências que fossem inovadoras do ponto de vista metodológico e fundamentalmente interdisciplinares, pois, dessa forma, poder-se-ia superar algumas das deficiências diagnosticadas nos processos de aprendizagem histórica no ensino básico. 
Dossiê: Ensino de História, História das Mulheres e Desigualdades Sociais no Brasil

Para alcançar estes objetivos de contribuir para subsidiar teóricometodologicamente os(as) bolsistas de ID na sua formação e futura atuação docentes, o subprojeto que teve início em 2014 contava com três linhas: "O ensino de História e os temas transversais", "Ensino de História e uso de fontes Históricas" e, "O exercício do ofício do historiador e a didática da História". Cada linha tinha um(a) coordenador(a) responsável por um terço dos 45 bolsistas, que atuaram em 9 escolas da cidade, com um(a) professor(a) supervisor(a) por escola, entre municipais e estaduais, do fundamental II ao Ensino Médio, todas na cidade de Uberaba/MG. A primeira destas linhas contemplou a articulação com o que estava proposto pelos Parâmetros Curriculares Nacionais (BRASIL, 1998), trazendo a perspectiva de formação interdisciplinar e a possibilidade de debates sobre as questões que envolviam gênero e história. Entretanto, nas outras linhas também pudemos observar este tema sendo abordado, muito por causa das próprias demandas dos envolvidos no subprojeto, dos(as) bolsistas aos(as) alunos(as) das escolas básicas. Dentre as ações deste período que tratavam da questão de gênero, vamos nos ater principalmente ao que foi desenvolvido no primeiro semestre de 2017, na Escola Municipal Monteiro Lobato, com alunos de $6^{\circ}$ a $9^{\circ}$ do ensino fundamental e na Escola Estadual Nossa Senhora da Abadia, com alunos(as) do Ensino Médio. Em ambos os casos o tema central eram as desigualdades observadas na sociedade, abordando problemas estruturais como o racismo, o machismo e a homofobia, dentre outros.

Entre os meses agosto de 2018 e fevereiro de 2020, já sob novo edital da Capes, o PIBID-História da UFTM continuou suas ações com relação ao trabalho das questões de gênero. Assim como nos anos anteriores, participaram do projeto estudantes dos anos finais do ensino fundamental (do $6^{\circ}$ ao $9^{\circ}$ ano) e Ensino Médio de escolas municipais e estaduais de Uberaba. No primeiro semestre de 2019 foi desenvolvido o projeto "A construção histórica do conceito de gênero e suas perspectivas no trabalho em sala de aula de forma interdisciplinar" em uma das escolas do projeto, a Escola Municipal Terezinha Hueb de Menezes. Os objetivos gerais desse projeto consistiram em permitir o aprofundamento de reflexões, a possibilidade de ações e execução de atividades com discussões sobre a historicidade das questões de gênero de forma 
Dossiê: Ensino de História, História das Mulheres e Desigualdades Sociais no Brasil interdisciplinar, aproximando o tema da realidade dos discentes e permitindo aos(às) bolsistas uma experiência com o tema em campo.

O objetivo deste artigo, portanto, é analisar algumas das experiências do subprojeto de História da UFTM, a fim de refletir sobre como foram trabalhadas as questões de gênero, e suas interseções com os debates sobre raça e racismo, em sala de aula pelos professores em formação, durante um período em que as políticas educacionais que tratam de gênero se tornaram polêmicas. Dessa forma, acreditamos poder reforçar o papel do PIBID frente a esses debates que estão postos na contemporaneidade e que exigem o preparo e atuação dos(as) futuros(as) professores(as) História. A tarefa se torna ainda mais relevante especialmente quanto a este tema, que teve grande visibilidade nos últimos anos, inclusive com o presidente tendo prometido combater a "ideologia de gênero" no seu discurso de posse no começo de 2019, fazendo com que seja imprescindível aos(às) professores(as) em formação que saibam lidar com este debate de forma responsável, promovendo um aprendizado significativo e capaz de transformar as realidades escolares.

\section{Uberaba e a questão de gênero nas escolas}

As ações do PIBID/História foram desenvolvidas em escolas da cidade de Uberaba, Minas Gerais. Assim como em outras cidades, também lá ocorreram intensos debates relacionados ao gênero e educação a partir de 2014, quando se estava discutindo no Congresso Nacional o Plano Nacional de Educação (PNE). Sobre este tema, já foram desenvolvidas pesquisas que trazem um panorama desta situação e reforçam a importância da educação formal e não formal para esclarecer a sociedade sobre gênero, visto que a sociedade aparentemente começou a temer aquilo que não entende, fazendo do debate de gênero algo visto como deletério por alguns setores sociais. (FERREIRA \& AGUIAR, 2018).

Conforme o debate se intensificou no espaço público nacional, a partir da aprovação do PNE com ressalvas às questões de gênero (até mesmo com a supressão da palavra em outros contextos do documento), estas discussões também passaram a ocorrer nas casas legislativas estaduais e municipais, com 
Dossiê: Ensino de História, História das Mulheres e Desigualdades Sociais no Brasil

a apresentação de inúmeros projetos de lei que visavam interditar qualquer tipo de relação entre gênero e educação. O combate ao que passou a se chamar de "ideologia de gênero" tornou-se central nos discursos de políticos e personalidades públicas conservadoras/reacionárias.

É difícil separar esta situação do que vinha ocorrendo no mundo todo naquele momento, com uma grande onda do pensamento conservador/reacionário, visando retomar uma ideia de sociedade tradicional especialmente contrária aos modelos de famílias e sociabilidades considerados desviantes e que vinham ganhando cada vez mais visibilidade, apesar de ainda grandemente marginalizados. A posição dos grupos e agentes políticos conservadores era uma reação ao protagonismo - ainda que tímido - que os grupos de excluídos vinham ganhando ao pressionarem, em todo o mundo, os Estados nacionais no sentido de promoverem uma educação mais inclusiva e transformadora da realidade desigual vivida.

São também os movimentos sociais, principalmente os de caráter identitário (indígenas, negros, quilombolas, feministas, LGBT, povos do campo, pessoas com deficiência, povos e comunidades tradicionais, entre outros), que, a partir dos anos de 1980, no Brasil, contribuem para a entrada do olhar afirmativo da diversidade na cena social. Eles reivindicam que a educação considere, nos seus níveis, etapas e modalidades, a relação entre desigualdades e diversidade. Indagam o caráter perverso do capitalismo de acirrar não só as desigualdades no plano econômico, mas também de tratar de forma desigual e inferiorizante os coletivos sociais considerados diversos no decorrer da história. (GOMES, 2012, p. 688).

Neste sentido, a demanda era de que as ações educativas ajudassem a combater a exclusão e preconceitos incentivando a convivência na pluralidade e o respeito às diferenças. Podemos dizer que durante os anos 1990 e primeira década de 2000 vivenciamos mudanças nas orientações epistemológicas das políticas públicas educacionais, com a adoção dos pressupostos de uma educação que navegasse neste sentido mais democrático e de promoção dos valores de respeito e tolerância, especialmente graças a ação dos movimentos sociais que buscavam apagar os resquícios do período autoritário anterior.

Infelizmente, estas ações não chegaram a se consolidar como políticas de Estado, ficando restritas a alguns governos e, logo após seu término, foram 
Dossiê: Ensino de História, História das Mulheres e Desigualdades Sociais no Brasil

amplamente combatidas e desmontadas, especialmente com o discurso que estariam promovendo algum tipo de "doutrinação ideológica", "destruindo os valores cristãos e a família tradicional", dentre outros argumentos que podem ser creditados a qualquer destes agentes políticos conservadores/reacionários que discursaram contra a ideologia de gênero - indo ao ponto mesmo de tentar impedir qualquer ação dos(as) educadores(as) como intelectuais, isto é, como mediadores dos saberes dos(as) alunos(as) com os saberes científicos. (PENNA \& FERREIRA, 2018)

Como consequência desse imaginário, a possibilidade de um sistema de ensino pautado no questionamento de preconceitos, discriminações e violências baseadas nos marcadores sociais de gênero e sexualidade se tornou objeto de "pânicos morais". Emergem, assim, investidas na defesa de uma moralidade sexual dominante contrárias à construção de uma agenda institucional voltada ao combate e à criminalização desses temas na escola, (des)caracterizados, nesse contexto, como "ideologia de gênero". Como parte da estratégia política do conservadorismo moral, várias proposições de lei têm sido apresentadas no Congresso Nacional e nas casas legislativas estaduais e municipais com o objetivo de avançar sobre as principais leis, documentos e diretrizes que balizam a educação no Brasil. Esses projetos, no intuito de institucionalizar práticas tagarelas de silenciamento, produzem leis que proíbem a abordagem e o questionamento dos marcadores sociais de gênero e de sexualidade por meio do campo educacional. (FERREIRA \& AGUIAR, 2018, p. 117).

Para além de verificarmos a procedência disso ou não, o que pudemos observar foi a mesma batalha política do campo educacional, lembrando a assertiva de Paulo Freire (1996) de que não há educação que não seja política, ideológica. Como tal, o debate sobre as políticas educacionais passou então a gravitar em torno desta questão sobre a pertinência ou não de se trabalhar as questões de gênero, com grandes reverberações em todo o país, inclusive em Uberaba.

Em 2015 foi feita uma alteração na Lei Orgânica do Município (Emenda n. 83/2015) segundo a qual "Não será objeto de deliberação qualquer proposição legislativa que tenha por objeto a regulamentação de política de ensino no Município, que tendam a aplicar a ideologia de gênero". De acordo com o estudo de Ana Laura da Silva Castro (2019), esta alteração foi fruto do engajamento dos 
Dossiê: Ensino de História, História das Mulheres e Desigualdades Sociais no Brasil grupos políticos conservadores locais, com o apoio de segmentos religiosos católicos e evangélicos, os quais teriam dado início ao processo solicitando audiência pública para discutir a inclusão da discussão de gênero no Plano Municipal de Educação. Definiam então os líderes daquele movimento a "ideologia de gênero", como o conjunto de ideias segundo as quais ninguém nasce homem ou mulher, e escolheria seu gênero durante a vida. Notável que esta afirmação esteve presente em muitos discursos políticos desde que começou a polêmica, alguns anos antes e, evidentemente, trata-se de uma forma vulgar de explicar um conceito histórico complexo de constituição das formas, sentidos e papéis de gênero ao longo do tempo nas sociedades humanas.

Em apenas quatro meses esses grupos conseguiram mobilizar a sociedade local e influenciar os debates entre os(as) vereadores(as), que acabaram aprovando a emenda em 17 de novembro de 2015. Nos meses anteriores à aprovação da emenda ficaram evidentes as disputas políticas em torno do debate sobre gênero, nem tanto por sua precisão teórico-metodológica - isto não interessava a estes interlocutores - mas muito mais pelo objetivo de espalhar o pânico moral identificado por Ferreira \& Aguiar (2018) e também analisado por Castro (2019) no estudo do caso uberabense. O projeto aprovado carecia de justificativas legais e atenta contra outras leis maiores, notadamente a própria constituição. Tanto é verdade que em abril de 2020 o Supremo Tribunal Federal considerou inconstitucional lei semelhante aprovada em Novo Gama, Goiás, algo que deve ter desdobramentos em outros municípios daqui por diante. Mesmo assim, continua vigente esta redação da Lei Orgânica que impede a regulamentação de políticas de ensino que tratem da questão de gênero.

Neste cenário, após todo este intenso debate, nacional e local, atuaram os bolsistas de ID do PIBID. A lei orgânica impede a implementação políticas educacionais municipais com abordagem de gênero no plano municipal, mas não interditaram que os projetos do PIBID o fizessem, especialmente por terem contemplados entre seus objetivos o tratamento de temas escolhidos em diálogo com os alunos atendidos. No próximo tópico vamos analisar como se deram estas ações e tentar entender se de alguma maneira esta proibição, ou as polêmicas do debate que suscitaram a própria mudança legislativa, apresentaram influências na maneira como se desenvolveram os trabalhos. 
A questão de gênero e suas abordagens no PIBID-História da UFTM

As diversas pesquisas desenvolvidas sobre gênero nos últimos anos foram uma ferramenta fundamental para o planejamento e execução das variadas atividades desenvolvidas pelos(as) bolsistas de ID no subprojeto. Não cabe no espaço deste texto uma discussão aprofundada sobre o conceito de gênero e de como ele foi se constituindo em ferramenta de análise por parte das historiadoras/historiadores, professores/professoras. Trata-se de um conceito dinâmico e que merece várias considerações a respeito dos seus múltiplos aspectos, mas no âmbito do PIBID ele foi tratado como um conceito relativo à maneira como se percebem as relações de poder entre homens e mulheres, uma construção social que deve ser analisada no plano cultural, isto é nas maneiras como se consolidam papéis masculinos e femininos ao longo do tempo, em outras palavras: "o gênero é um campo primário no interior do qual, ou por meio do qual, o poder é articulado" (SCOTT, J. 1995, p. 88)

As leituras e discussões sobre a bibliografia específica sempre foram destacadas pelos coordenadores na estruturação das atividades e nas reuniões formativas do grupo. Além da ferramenta teórica, os grupos de bolsistas buscaram referências nas observações do cotidiano escolar para a escolha de metodologias e estratégias específicas para a turma participante.

No campo teórico, os(as) bolsistas puderam realizar debates sobre como as questões de desigualdades de gênero, sexualidade, raça e classe - e também todas as interseções entre estas categorias - tornaram-se, nos últimos anos, espaços de disputa sobre os comportamentos, de demarcação de limites do que seria ou não considerado, digamos, aceitável no meio social, uma clara configuração de disputas de poderes sobre os corpos. Neste cenário, temos

A escola, como local privilegiado de exercício de discursos pautados em relações societais, constitui-se como um campo tanto de reprodução quanto de contestação das hierarquias, e é preciso perceber como isto ocorre, para tornar efetivo o combate às desigualdades. $\mathrm{O}$ discurso institucional, o material didático, bem como as relações professor-aluno e as estabelecidas entre os grupos de pares apresentam-se como locus de atualizações da sociedade mais ampla, apontando para a necessidade de 
Dossiê: Ensino de História, História das Mulheres e Desigualdades Sociais no Brasil

percebermos a escola como um importante lugar que oferece a sua própria configuração de relações de poder. É neste sentido que o lugar privilegiado para repensar essas hierarquias é no diálogo com as reflexões e interpretações das experiências trazidas por professores, bem como uma conscientização de suas várias formas de expressão e implicações para os grupos situados em posições diversas, frequentemente marginais, não somente na escola, mas também fora dela. (LEWIS, SCOTT \& QUADROS, 2009, p. 15)

Esta observação a respeito do espaço escolar era compartilhada pelos(as) bolsistas de ID, alguns dos quais se encontravam engajados em movimentos sociais - feministas, negros, LGBT (Lésbicas, Gays, Bissexuais, Travestis, Transexuais e Transgêneros), entre outros - ou reconheciam estes como interlocutores importantes no seus processos de formação. Sendo assim, nos encontrávamos diante da possibilidade de fazer cumprir os objetivos do curso de História e do próprio PIBID, aliando teoria e prática durante o processo de formação docente.

Dentre as diversas ações realizadas com a temática de gênero, vamos analisar agora duas delas que foram desenvolvidas durante o ano de 2017. Os(as) bolsistas de ID que atuavam na escola municipal Monteiro Lobato e na estadual Nossa Senhora da Abadia, ambas em Uberaba, desenvolveram projetos de intervenção que buscavam discutir as várias desigualdades e a diversidade presentes na sociedade brasileira durante os séculos de sua formação social, possibilitando a reflexão histórica sobre estas questões no presente.

A primeira turma atuou na Escola Municipal Monteiro Lobato, cujos alunos(as) estavam no Ensino Fundamental II. Orientados pelo supervisor e coordenador, foram criadas oficinas e debates em formato de rodas de conversa, na qual se estabeleceram diálogos horizontais, a partir dos quais foi possível levantar as questões consideradas relevantes pelo grupo de alunos(as) atendidos(as) e, como forma de avaliação da aprendizagem, estes produziram desenhos, poemas ou textos com suas impressões. O tema era a diversidade e desigualdade e foram abordadas questões raciais e de gênero, muitas das vezes com interseções entre eles.

As atividades começaram ajudando os(as) alunos(as) a entender a historicidade da condição social feminina e como ela foi se alterando. Para isso 
Dossiê: Ensino de História, História das Mulheres e Desigualdades Sociais no Brasil preparam slides com imagens, músicas, poesias e exemplos de mulheres que participaram de diversos movimentos sociais ao longo do tempo. Foram convidadas a falar militantes de movimentos feministas presentes na universidade, na tentativa de problematizar situações do dia a dia em que o machismo está presente, promover uma discussão com os(as) estudantes sobre a atualidade do tema e como ele tem impactos na vida de todos. Foi uma maneira de envolver os(as) alunos(as) no processo de construção do conhecimento histórico, à medida que entendiam como suas vidas no presente foram constituídas por ações passadas.

Na sequência foram realizados os debates e atividades sobre a questão LGBT com a seguinte dinâmica: a turma de estudantes escutavam uma situação sobre atitudes preconceituosas e, em seguida, por sorteio, era dividida em grupos para tentar argumentar contra ou a favor da dada situação que ao final era discutida por todos de forma livre, problematizando a atitude de preconceito, tentando entender quais razões levam a pessoa ter uma atitude preconceituosa e como reverter este tipo de atitude para algo mais humano e respeitoso. Após isso, foi realizada exposição e debate sobre o Movimento LGBT, sua história e significado da sigla, os impactos sociais das exclusões desta população e a produção artística engajada correlacionada ao tema.

Depois de finalizadas as oficinas e debates, no último encontro foram produzidos pelos(as) alunos(as) os textos, desenhos e o que mais quisessem para que pudessem se expressar quanto ao que havia sido debatido. Os resultados foram expostos no "Varal da Diversidade". Nas colagens produzidas destacamos duas frases escolhidas pela turma de estudantes: "lugar de mulher é onde ela quiser" e "qualquer forma de amor é linda". Estes dois exemplos nos remetem à constatação de que os(as) alunos(as) puderam desenvolver reflexões sobre a historicidade do conceito de gênero e as derivações que ele permite, fazendo-nos, enquanto sociedade, entender e quebrar padrões tidos como universais.

A outra atividade foi realizada pelos(as) bolsistas de ID que atuaram na Escola Estadual Nossa Senhora da Abadia com alunos(as) do Ensino Médio; fazia parte de um projeto de intervenção aplicado no correr de 2017, no qual foram debatidas as desigualdades observadas no presente e como elas se 
Dossiê: Ensino de História, História das Mulheres e Desigualdades Sociais no Brasil constituíram historicamente. Além de proporcionarem estudos sobre as questões de gênero, o grupo de bolsistas ID trabalhou com os preconceitos racial, de religião, sociais e políticos.

Gênero começou a ser debatido a partir das reflexões sobre as desigualdades entre homens e mulheres. Produziu-se um blog no qual foi apresentada a atividade sobre preconceito de gênero, a qual consistiu na análise do documentário "Precisamos falar com os homens?". Esta obra é uma iniciativa da ONU Mulheres e da ONG PapodeHomem, tem como mote principal a discussão sobre a desigualdade de gênero, apresentando as muitas maneiras pelas quais as mulheres são colocadas em situações de inferioridade em relação aos homens. Também se propõem especialmente em fazer com que os homens repensem seus papéis e entendam de que forma podem mudar.

O objetivo do blog era registrar a percepção dos(as) alunos(as) em relação aos temas trabalhados nas oficinas. Portanto, de certa forma, este espaço virtual serviu como uma maneira de avaliar os resultados das discussões, o que ajudou no direcionamento das oficinas posteriores. Vamos analisar, então, como se deram essas oficinas antes de observarmos mais detidamente às respostas dos(as) estudantes no blog.

Nas oficinas os(as) bolsistas de ID fizeram exposição de questões para reflexão junto a alguns dados sobre discriminação de gênero. O objetivo principal era ajudar os(as) participantes a perceberem a historicidade das relações de poder entre homens e mulheres, como isso se apresenta nos ambientes de trabalho e, por fim, quais consequências a discriminação de gênero traz para a sociedade. Para este fim, foram discutidos temas e conceitos como a divisão de trabalho, papéis sociais masculinos e femininos, violência contra as mulheres e, ao final, propôs-se a discussão da música cuja letra trazia logo no início a mensagem principal para reflexão: “Triste, louca ou má, será qualificada, ela quem recusar, seguir receita tal" (Francisco, El Hombre, 2016). Segundo o relato dos(as) bolsistas, os(as) alunos demonstraram interesse e apresentaram uma intensa participação nos debates, os quais foram feitos oralmente.

As análises dos(as) alunos(as) e a crescente percepção de identificação com os temas podem ser notadas a partir das respostas que deram ao blog acima referenciado "Precisamos falar com os homens". Foram enviadas 18 
Dossiê: Ensino de História, História das Mulheres e Desigualdades Sociais no Brasil

respostas a esta postagem específica, infelizmente não temos o registro da quantidade total de alunos(as) que participaram das oficinas presenciais, mas para termos uma ideia, a postagem que teve maior participação foi a de preconceito religioso, com 75 respostas. Mas, por outro lado, a maioria das respostas desta postagem eram idênticas, mostrando que muitos deles copiaram da mesma fonte e pouco se importaram em desenvolver reflexões próprias. $\mathrm{Na}$ parte sobre gênero, em várias respostas foram registrados pensamentos e impressões pessoais. Sendo assim, há uma diferença qualitativa que nos leva à hipótese de que a questão de gênero levantou maior interesse em debater por parte daqueles alunos(as). Também chama a atenção na postagem sobre gênero que somente 2 das 18 respostas foram enviadas por adolescentes do sexo masculino, algo que pode ter múltiplas causas - que inclusive deve ser problematizado pelo fato de que não podemos saber a qual identidade de gênero as pessoas se reconhecem somente pelo nome civil - mas certamente é sinal de que o tema tem impactos diferentes em homens e mulheres. Observemos algumas das respostas abaixo:

[...] Eu particularmente sou a favor da igualdade social e política entre ambos os sexos, um homem não é diferente de uma mulher e uma mulher não é diferente de um homem. Certos conceitos e pensamentos são formados de séculos atrás, e é cultivado dentro de casa quando sua mãe inconcentimente ensina ao filho que é a irmã que lava a louça, por que? Porque ela é uma garota, isso é papel de mulher! Mulher decente é claro, aquela que se presa, usa a roupa adequada, cuida dos filhos e da casa. (Gabrielle, Segundo ano do Ensino Médio, grifo nosso)

Infelizmente, atualmente é muito comum vermos e convivermos com o preconceito de gênero, a cada dia que passa a mente das pessoas se fecham cada vez mais, e isso acontece devido aos padrões herdados por nossos antepassados que não eram acostumados com o mesmo convívio social que nós somos hoje, o que hoje não justifica de forma alguma, em pleno século $\mathrm{XXI}$ alguém ainda tratar um outrem com falta de respeito ou reconhecimento apenas pela sua opção sexual. (Raissa, Terceiro ano do Ensino Médio, grifo nosso)

O preconceito de gênero é um assunto tão importante para nossa sociedade. Âs vezes ficamos desmotivados com tanta violência e preconceito de gêneros no nosso cotidiano... Mas é tão reconfortante saber que existem tantas pessoas e instituições representando e gerando reflexões sobre esses problemas. Quem tem capacidade de reflexão daí podem inferir 
Dossiê: Ensino de História, História das Mulheres e Desigualdades Sociais no Brasil

uma realidade, de desigualdade no tratamento entre homens e mulheres, que apesar de existente a tanto tempo são vista como natural e inquestionáveis e até então imperceptíveis, isto é, é bem possível q nunca se tenha refletido sobre tudo exposto nas falas do participantes do vídeo. (lago, Terceiro ano do Ensino Médio, grifo nosso)

Os grifos que fizemos nestes relatos dos(as) alunos(as) demonstraram que o objetivo de entender a historicidade das relações de poder entre homens e mulheres está explícita. Seja por terem assistido ao documentário ou participado das oficinas, o que importa, ao nosso ver, é que se entre os(as) alunos(as) uma identificação com aquela maneira de contar as histórias, com aqueles problemas, e eles passaram a refletir historicamente a respeito das consequências e possibilidades de solução. Esta identificação está evidente nos exemplos que dão, uma delas fala sobre a imposição de papéis sexuais, como os serviços domésticos às mulheres, o garoto cita que a situação de desigualdade é vista como natural, inquestionável, imperceptível, demonstrando que esta reflexão até então não tinha sido colocada durante sua formação pessoal.

Em todas as atividades acima analisadas os(as) bolsistas relataram 0 especial interesse que os(as) alunos(as) demonstraram sobre o tema e como conseguiram se identificar com aquelas histórias sendo contadas, mesmo que não todos eles(as) diretamente. Vemos como, na prática, puderam se perceber enquanto agentes históricos, como pessoas que são o que são, pois suas histórias foram escolhidas ser contadas de uma maneira em que nem sempre eles poderiam fazer parte, tampouco como protagonistas. Foi possível através das oficinas refletir sobre a constituição das identidades e de como este processo se configura em um espaço de lutas por "reconhecimento entre indivíduos, grupos, sociedade, culturas, que não podem dizer o que são, sem ter de dizer, ao mesmo tempo, quem ou o que são os outros com os quais têm a ver" (RÜSEN, 2010, p. 87). Em outras palavras, os(as) alunos(as) e bolsistas puderam trabalhar com a consciência histórica e, ao mesmo tempo, entender parte do processo de constituição de uma narrativa acadêmica sobre o passado e como aquilo se relaciona com eles.

Essa percepção do papel da consciência histórica e da importância relativa às questões de gênero levou à continuidade de propostas de práticas de 
Dossiê: Ensino de História, História das Mulheres e Desigualdades Sociais no Brasil ensino relacionadas a essas propostas no subprojeto referente ao Edital 20182019. Alguns projetos incluíram a temática, mas o foco aqui será nas ações realizadas na Escola Municipal Terezinha Hueb de Menezes por tratar a questão especificamente. Já no início do desenvolvimento do subprojeto os(as) bolsistas da escola trabalharam a temática sobre o racismo que contemplou como subtemas, os(as) grandes ícones contra o racismo e a apresentação sobre a luta das mulheres negras contra o racismo. Dessa sequência didática, resultou em uma roda de conversa sobre as experiências de cada discente com o racismo. O grupo de bolsista incluía uma discente vinculada ao movimento negro da cidade que tem uma forte atuação em escolas, o que facilitou o encaminhamento da roda, enquanto espaço de abertura e diálogo entre bolsistas e estudantes. Nessa roda de conversa ela trouxe um debate importante da interseccionalidade de raça e gênero. Kimberle Crensahw ressalta que: "precisamos desagregar os dados de raça e gênero e ter certeza de que sabemos diferenciar o que está acontecendo em função de questões raciais e em função de questões de gênero" (CRENSHAW, 2004, p. 16). Esse embasamento e a reflexão das falas do grupo de estudantes levaram à compreensão de que merecia um aprofundamento sobre discussões de gênero.

Assim, no primeiro semestre de 2019 a retomada da discussão de gênero foi reforçada pelo grupo que buscou trabalhar através de uma abordagem de transversalidade. Essa abordagem surgiu de discussões realizadas no evento "Multidisciplinar do PIBID-UFTM: construindo laços educacionais", que proporcionou um espaço de debates relacionados ao desenvolvimento de projetos, práticas, experiências e ações inter/multidisciplinares pelos projetos disciplinares e multidisciplinares.

O evento ocorreu nos dias 7 e 8 de fevereiro de 2019 e contou com a participação de todos os(as) envolvidos(as) no Projeto PIBID-UFTM. Sua programação contemplou diversas atividades, apresentações artístico-culturais, mesa redonda e Grupos de Trabalho (GTs) temáticos, entre os quais figurava um sobre "Pluralidade cultural, ensino e gênero". Para finalizar, ocorreu a reunião separada de cada subprojeto do PIBID para congregar as discussões empreendidas no evento e planejar as ações inter/multidisciplinares de 2019. Mesmo não se enquadrando no edital multidisciplinar, os(as) envolvidos no 
Dossiê: Ensino de História, História das Mulheres e Desigualdades Sociais no Brasil

subprojeto de História consideraram enriquecedor e desafiador o trabalho interdisciplinar. A partir desta atividade, foi possível sistematizar reflexões no grupo acerca das definições e da importância dos trabalhos inter/multidisciplinares na produção de conhecimento e na educação:

Unidades complexas, como o ser humano ou a sociedade, são multidimensionais: dessa forma, o ser humano é ao mesmo tempo biológico, psíquico, social, afetivo e racional. A sociedade comporta as dimensões histórica, econômica, sociológica, religiosa... O conhecimento pertinente deve reconhecer esse caráter multidimensional e nele inserir estes dados (...) (MORIN, 2003, p. 38).

A perspectiva globalizante de Morin, de necessidade de correspondência entre as problematizações educacionais e a realidade multidimensional da vida, foi bem recebida no grupo de bolsistas. Isso foi percebido na contextualização dos participantes, nos relatos e diagnósticos. Percebemos a necessidade de aproximar esse debate do ensino de História. Dessa forma, associaram essa abordagem para o foco das questões de gênero. As ações foram planejadas por duplas de bolsistas do PIBID a cada semana com a orientação de supervisor e coordenadores de área em uma das escolas.

O trabalho inter/multidisciplinar na sala de aula é tema referenciado há tempos no campo do ensino. No entanto, o desenvolvimento prático ainda se apresenta como obstáculo para os(as) professores(as). Para Lima e Azevedo, as disciplinas são complementares, mas essa articulação apresenta-se desafiadora para docentes por preocupações com o currículo, a exposição de 'fraquezas' e o rompimento com a rotina (LIMA \& AZEVEDO, 2013, p. 144).

Selva G. Fonseca apresenta as diferenças nas abordagens multidisciplinar, interdisciplinar e transdisciplinar. A autora ressalta que é mais tradicional $\mathrm{o}$ trabalho multidisciplinar que mantém a independência das disciplinas com a indicação de conteúdos que formam um todo, mas que não são apresentados explicitamente nas suas relações estabelecidas (FONSECA, 2009 , p. 106). E, no caso da interdisciplinaridade contempla um trabalho de "integração entre os conteúdos e as metodologias de disciplinas diferentes que se propõem a trabalhar conjuntamente determinados temas. Não é uma simples fusão ou justaposição, mas uma 'interpenetração' de conceitos, dados e 


\title{
HISTÓRIA
}

Dossiê: Ensino de História, História das Mulheres e Desigualdades Sociais no Brasil

metodologias" (FONSECA, 2009, p. 106). Outra possibilidade metodológica é a transdisciplinaridade e sobre o assunto, Fonseca coloca que:

trabalhar o ensino por meio de projetos, assumindo a transversalidade entre os campos de saber, passa por assumir uma postura político-pedagógica na qual a formação dos indivíduos seja pensada como um processo em que diversas instâncias, diversos campos do saber se entrelaçam, intervindo, transmitindo, construindo o pensamento. Significa 'transitar pelo território dos saberes', possibilitando a recuperação da totalidade do ato de conhecer (FONSECA, 2009, p. 107).

O projeto desenvolvido teve esse caráter transdisciplinar ou transversal. Assim, a proposta de atividades relacionadas à questão de gênero segue a posição de que:

\begin{abstract}
A busca da compreensão da realidade e a efetiva participação do indivíduo a partir de dados e noções relativos ao seu cotidiano, ao seu universo, fazem com que a escola passe a ser considerada como um espaço de conhecimento e reconhecimento, onde por intermédio das diversas disciplinas e de sua nova abordagem o aluno seja capaz de ver e vislumbrarse como construtor de sua própria história (NETO, 2016, p. 66).
\end{abstract}

A prática da trans/inter/multidisciplinaridade é um obstáculo na educação brasileira. Muito se fala, mas na prática pouco se concretiza. O evento do PIBIDUFTM proporcionou avançar no debate entre as diversas áreas que o contempla. Possibilitou encaminhar os(as) bolsistas de Iniciação à Docência em uma perspectiva mais ampla de ensino de História. Partiu-se da abordagem transdisciplinar com a ideia de que:

O importante é fornecer aos estudantes elementos para um 'olhar de gênero', ou seja, fazer com que eles percebam como o masculino e o feminino têm sido e ainda são representados e, a partir disso, como as sociedades se organizam com base nessas representações. Estamos falando das questões de gênero (PINSKY, 2015, p. 29).

O projeto desenvolvido pelo grupo do PIBID-História da E.M. Terezinha Hueb de Menezes incluiu a integração com o PIBID-Ciências Biológicas, também atuante na escola, tratando sobre o feminismo e o corpo humano. Essa 
Dossiê: Ensino de História, História das Mulheres e Desigualdades Sociais no Brasil integração foi uma etapa importante, pois conseguiu esclarecer para a turma a distinção entre o conceito de sexo e gênero e trouxe a perspectiva do corpo e sua relação com as mulheres. Questões diversas surgiram na oficina e que foram respondidas aos olhos dos diversos campos do saber, como: sexualidade, prazer, saúde, padrão de beleza etc.

Além dessa atividade, o projeto contemplou o trabalho sobre gênero relacionado com mídias e, iniciou-se com o foco nas Princesas da Disney e a reflexão com o momento histórico referente a criação e a perpetuação de cada uma. Durante a atividade seguiram a seguinte linha cronológica:

- Princesas clássicas (1937-1959): Branca de Neve, Cinderela e Bela Adormecida;

- Princesas rebeldes (1989-1998): Ariel, A Bela e a Fera, Pocahontas e Mulan;

- Princesas contemporâneas (2009-2012): A Princesa e o Sapo, Enrolados, Valente e Fronzen.

A escolha do tema princesas relacionou-se com a concepção de contemplar a realidade estudantil. As princesas são produtos midiáticos que marcaram a infância de várias gerações. Além disso, moldaram a concepção de gênero inconscientemente. A atividade usou recursos audiovisuais e exibição de trechos cinematográficos para a exposição das ideias e ativação dos posicionamentos estudantis. A partir dela, foi possível esclarecer dúvidas e ativar associações com outras manifestações midiáticas que envolvem o gênero.

Seguindo o cronograma de atividades, a próxima dupla de bolsistas tratou com o grupo de estudantes sobre a diversidade de gênero. Iniciaram com a discussão com as ideias de liberdade e igualdade e atrelaram à exposição os movimentos feministas e LGBT e seus históricos. Usaram vídeos curtos para as reflexões empreendidas.

Prosseguindo nas propostas do projeto passou-se para o tema História dos direitos das mulheres, da Antiguidade aos dias atuais. A dupla responsável trouxe um histórico sobre os Direitos das mulheres e para finalizar construíram um jogo de tabuleiro com marcos históricos importantes para as mulheres. 0 jogo foi ilustrado com iconografias que possibilitaram refletir sobre o tema em questão. $\mathrm{O}(\mathrm{a})$ estudante ao jogar o dado cairia em alguma casa e seria destinado a fazer algo. A primeira casa, por exemplo, colocava: 
Dossiê: Ensino de História, História das Mulheres e Desigualdades Sociais no Brasil

- 1428: PRIMEIRO JULGAMENTO DE PESSOAS ACUSADAS COMO

BRUXAS. Xiii, você como mulher foi condenada à fogueira. Aqui as meninas não têm vez, se você é mulher volte para o início do jogo.

Cada casa trouxe aos participantes do jogo elementos dos obstáculos e conquistas das mulheres ao longo do tempo. O jogo propiciou reações diversas, como por exemplo, irritabilidade das meninas com os fatos históricos apresentados. Mas o principal foi a compreensão geral dos preconceitos e enfrentamentos que ao longo da história as mulheres vivenciaram, e que apesar das conquistas ainda vivenciam uma realidade misógina e não igualitária.

As atividades desenvolvidas incluíram os diversos aspectos das questões de gênero. Buscaram uma abordagem transversal e uma aproximação e reflexão a partir das visões de mundo desses jovens. Mas, para além dos resultados nas escolas é preciso pontuar o papel do PIBID na formação de futuros(as) profissionais da educação.

\section{Considerações Finais}

A contemporaneidade exige um papel ativo de docentes para enfrentar os desafios postos na educação. Entre esses desafios está a abordagem de gênero que, nos últimos anos vem sofrendo ataques constantes em todo o país. Apresentamos o desencadeamento dos debates em Uberaba, município em que foram desenvolvidas as atividades do subprojeto de História do PIBID e pudemos perceber que os impactos dessa polêmica, apesar de trazerem consequências ruins, como o entendimento raso sobre o tema, também fez com que aumentasse o interesse por parte dos(as) alunos(as), que viam nessa discussão uma questão significativa em suas vidas e sobre a qual gostam de saber mais. Nesse sentido, os(as) bolsistas puderam propor mais debates e construção de conhecimento dialogado, além de mobilizarem conhecimentos de diversas áreas: leituras e práticas da trans/inter/multidisciplinaridade, que desenvolvem habilidades essenciais para os professores em formação no contexto atual.

Sendo assim, os resultados do trabalho com as questões de gênero reforçam o papel do PIBID nas escolas e na formação de professores(as). Os(as) licenciandos(as), ao desenvolverem os trabalhos, puderam se aprofundar na 


\section{HISTÓRIA}

Dossiê: Ensino de História, História das Mulheres e Desigualdades Sociais no Brasil compreensão dos conceitos relativos ao projeto e, mais importante, conseguiram compreender e executar o papel que o(a) professor(a)/pesquisador(a) deve ter na sala de aula, qual seja, o de intermediar diversos saberes para um processo de construção coletiva da compreensão sobre as desigualdades de gênero.

Fica também evidenciado com este texto, mais uma vez, que o PIBID é, possivelmente, um dos programas de maior sucesso que obtivemos na história da educação brasileira, pois possibilitou formar professores(as) mais bem preparados(as) para a atuação na escola e que puderam aprender na prática como fazer as pontes entre o que aprendiam e discutiam nas salas da universidade para as salas de aula. Em meio a grandes polêmicas a respeito do ensino de gênero, os(as) licenciandos(as) mostraram a relevância que têm na formação docente a busca por apuro teórico aliada à uma postura dialógica e que busca construir dinamicamente as metodologias de intervenção na escola. Somente veremos os impactos desta atuação nas próximas gerações, mas é certo que não há mais como voltar ao mundo idealizado pelos reacionários em que esta questão era escondida e os preconceitos e a violência de gênero eram naturalizadas.

\section{Referências}

Vídeos:

Francisco, El Hombre. Triste, Louca ou Má. São Paulo: independente, 2016. Disponível em https://youtu.be//KmYTHgBNoE. Acesso: 10 de junho de 2020.

PRECISAMOS falar com os homens?. Direção de lan Leite e Luiza de Castro. São Paulo: Monstro Filmes, 2016. Disponível em

https://youtu.be/jyKxmACaS5Q. Acesso: 10 de junho de 2020.

Blog

BLOG DE HISTÓRIA. http://pibidhis.blogspot.com/2017/07/preconceito-degenero-oficina-i.html. Acesso: 10 de junho de 2020.

Livros e Artigos: 


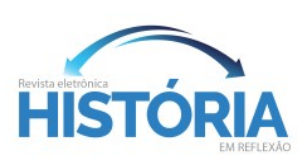

Dossiê: Ensino de História, História das Mulheres e Desigualdades Sociais no Brasil

BRASIL Secretaria de Educação Fundamental. Parâmetros curriculares nacionais: temas transversais. Secretaria de Educação Fundamental. Brasília: MEC / SEF, 1998.

CASTRO, Ana Laura da Silva. Gênero e Educação: uma análise histórica do processo de aprovação da Emenda n. 83/2015 à Lei Orgânica do Município de Uberaba-MG. Uberaba: UFTM, 2019 (TCC - curso de História).

CRENSHAW, K. W. A Intersecionalidade na discriminação de raça e gênero. In: Cruzamento: raça e gênero. Brasília: Unifem, 2004. Disponível em: http://acaoeducativa.org.br/fdh/wp-content/uploads/2012/09/KimberleCrenshaw.pdf - Acesso 14/06/2020.

FERREIRA, Camila Camargo; AGUIAR, Márcio Mucedula. "Ideologia de gênero": pânicos morais, silêncios tagarelas e a (re)produção de normas binárias de gênero. Revista Ñanduty, [S.I.], v. 6, n. 8, p. 114-143, set. 2018. ISSN 2317-8590. Disponível em:

<http://ojs.ufgd.edu.br/index.php/nanduty/article/view/8838/4641>. Acesso em: 09 jun. 2020. doi:https://doi.org/10.30612/nty.v6i8.8838

FONSECA, Selva G. Didática e Prática de Ensino de História: experiências, reflexões e aprendizados. 8ª . ed. Campinas: Papirus, 2009.

GOMES, Nilma Lino. Desigualdades e diversidade na educação. Educ. Soc., Campinas , v. 33, n. 120, p. 687-693, set. 2012 . Disponível em <http://www.scielo.br/scielo.php?script=sci arttext\&pid=S010173302012000300002\&lng=pt\&nrm=iso $>$. acessos em 10 jun. 2020. https://doi.org/10.1590/S0101-73302012000300002.

LEWIS, Liana. SCOTT, Parry, QUADROS, Marion Teodósio de. Diversidade, Diferença desigualdade e educação. In: (orgs). Gênero, diversidade e desigualdades na educação: interpretações e reflexões para a formação docente. Recife: Publicações Especiais do Programa de Pós-graduação em Antropologia/FAGES, Ed. UFPE, 2009.

LIMA, Aline Cristina da Silva. AZEVEDO, Crislane Barbosa. A interdisciplinaridade no Brasil e o ensino de História: um diálogo possível. Revista Educação e Linguagens, Campo Mourão, v. 2, n. 3, jul./dez. 2013.

MORIN, Edgar. Os sete saberes necessários à Educação do Futuro. $8^{\mathrm{a}}$. ed. São Paulo: Cortez; Brasília: UNESCO, 2003.

NETO, José Alves de Freitas. A transversalidade e a renovação no ensino de História. In: KARNAL, Leandro (org.). História na sala de aula: conceitos, práticas e propostas. São Paulo: Contexto, 2016

PENNA, Fernando de Araújo; FERREIRA, Rodrigo de Almeida. O trabalho intelectual do professor de história e a construção da educação democrática: práticas de história pública frente à base nacional comum curricular e ao escola sem partido. In: MENESES, Sonia; ALMEIDA, Juniele Rabêlo de (org.).

História pública em debate: Patrimônio, educação e mediações do passado. São Paulo: Letra e Voz, 2018. p. 109-127 


\section{HISTÓRIA}

Dossiê: Ensino de História, História das Mulheres e Desigualdades Sociais no Brasil

PINSKY, C. B. Gênero. PINSKY, C. B. (org.). Novos temas nas aulas de História. São Paulo: Contexto, 2015.

ROCHA, I. P. SILVA, M. de S. PIBID História na UFTM: velhos e novos desafios na formação docente. BUENO, A. CAMPOS, C. E. CREMA, E. NETO, J. M. de S. In: Aprendendo História: Experiências. União da Vitória: Edições Especiais Sobre Ontens, 2019, pp. 160-164.

RÜSEN, Jörn. Razão Histórica. Teoria da História: os fundamentos da ciência histórica. Brasília: Ed UnB, $1^{a}$ reimpressão, 2010.

SCOTT, Joan. Gênero: uma categoria útil de análise histórica. Educação e Realidade, Porto Alegre, v.20, n.2, p. 71-99, jul./dez. 1995

SILVA, M. de S. COSTA, R. de F. OLIVEIRA, T. F. B. N de. Teoria e prática na formação de professores de História na UFTM: considerações sobre a contribuição do PIBID. In: FREIRE, D. de J. VIEIRA, R. F. HALLEY, T. (orgs).

Formação inicial e continuada no contexto do PIBID-UFTM. São Paulo:

Oitava Rima. Uberaba: UFTM, 2018, pp. 47-63. 